\title{
El testimonio: lengua, verdad y subjetividad. Una aproximación entre Foucault y Agamben
}

\author{
Magali Haber \\ Universidad de Buenos Aires-Instituto Gino Germani / CONICET/ Universidad \\ Nacional de Lanús, Argentina
}

\begin{abstract}
Resumen
El presente texto indagará en los conceptos de testimonio, verdad, potencia y lengua e infancia a partir de un recorrido por los desarrollos teóricos de Giorgio Agamben y Michel Foucault para repensar la noción de sujeto a partir de la figura del testimonio. Se recorrerán los textos La verdad y las formas jurídicas de Foucault para rastrear la conformación del testimonio en tanto tecnología política o práctica de saber-poder y a continuación se transitarán varios pasajes de la obra de Agamben para retomar tal figura en su relación con el lenguaje, la potencia y la vida para arribar a la tensión entre subjetivación y desubjetivación característica, según tal autor, de todo testimonio. Hacia el final algo de El pensamiento del afuera resonará en las palabras de Agamben en torno al testimonio y la lectura.
\end{abstract}

\begin{abstract}
This paper will inquire in the concepts of testimony, truth, potentiality, language, and infancy, following the developments of Giorgio Agamben and Michel Foucault on biopolitics to rethink the notion of subject trough the figure of testimony. The text Truth and the legal forms of Foucault will be traversed to trace the conformation of the testimony as political technology or practice of knowledge-power and then several passages of the work of Agamben will be traced to retake such figure in its relation with the language, power and life to arrive at the tension between subjectivation and desubjectivation that crosses all testimony. Towards the end something of The Thought of the Outside will resonate in the words of Agamben around testimony and reading.
\end{abstract}

Michel Foucault en La verdady las formas jurídicas traza una genealogía de la verdad y a partir de ésta última propone, siguiendo a Nietzsche, una reelaboración de la teoría del sujeto. El sujeto deja de ser considerado como el punto de origen o el lugar donde eclosiona una verdad; es decir, el fundamento que permitía la presuposición de un conocimiento idéntico en su forma a lo largo de la historia. El autor, por lo tanto, recorriendo diferentes prácticas judiciales, va desplegando diversas formas o juegos

Palabras clave

Agamben Foucault testimonio subjetividad lengua

\section{Keywords}

Agamben Foucault testimony subjectivity language 
de verdad que muestran relaciones cambiantes entre el sujeto y la verdad. Las nociones de individuo, sujeto de conocimiento, así como las formas de conocimiento que definen y producen lo humano como conocimiento, no pueden ser comprendidas por fuera de tales formas jurídicas -que han sido las privilegiadas, en campo más vasto de las prácticas sociales en general, en la producción de formas de veridicción. Una hipótesis fuerte de la Primera Conferencia es que las prácticas sociales engrendran dominios de saber, que dan lugar a objetos, técnicas y conceptos.

Desvinculándose de las interpretaciones psicoanalíticas Foucault plantea que con Edipo el pueblo se apodera del derecho de juzgar, de oponer la verdad a sus gobernantes, es decir a juzgarlos: "El testigo, el humilde testigo, puede por sí solo, por medio del juego de la verdad que vio y enuncia, derrotar a los más poderosos" (Foucault, 2008).

Así, cuando el poder es tachado de ignorancia, inconsciencia, olvido, oscuridad, por un lado quedará el adivino y el filósofo en comunicación con la verdad, con las verdades eternas de los dioses o del espíritu, y por otro estará el pueblo que, aun cuando es absolutamente desposeído del poder, guarda en sí el recuerdo o puede dar testimonio de la verdad. Así, para ir más allá de un poder que se encegueció como Edipo, están los pastores que recuerdan y los adivinos que dicen la verdad (Foucault, 2008: 60-61).

Surge así el derecho de dar testimonio, de oponer la verdad al poder. Tal oposición de verdad sin poder a poder sin verdad ocasionó la emergencia de nuevas formas culturales, más precisamente la elaboración de las formas racionales de la prueba y la demostración y la retórica:

Cómo producir la verdad, en qué condiciones, qué formas han de observarse y qué reglas han de aplicarse. Estas formas son la filosofía, los sistemas racionales, los sistemas científicos. En segundo lugar, y en relación con estas formas que hemos mencionado, se desarrolla una arte de persuadir, de convencer a las personas sobre la verdad de lo que se dice, de obtener la victoria para la verdad o, aún más, por la verdad. Nos referimos a la retórica griega. En tercer lugar está el desarrollo de un nuevo tipo de conocimiento: conocimiento por testimonio, recuerdos o indagación (Foucault, 2008: 67).

Esta mutación, que tuvo lugar en la sociedad griega en el siglo V, produjo un desmantelamiento de la "gran unidad formada por el político y el saber" (Foucault, 2008: 60). El resultado fue una forma de descubrimiento judicial, jurídico de la verdad, que pasó a constituir el punto de partida para otros saberes (filosóficos, retóricos, empíricos). Sin embargo, la indagación cayó en desuso tras la caída del imperio romano y fue retomada, bajo otra forma, recién en la segunda mitad de la Edad Media.

En la Edad Media, según el derecho germánico previo a la invasión del imperio romano, los litigios se reglaban por el juego de la prueba (que implicaban pruebas corporales, pruebas sociales así como la correcta pronunciación de fórmulas verbales). El derecho era una forma reglada de encadenar actos de venganza, un modo pautado de hacer la querra a la que una transacción ponía fin. No existía la posición de un tercero neutro que buscase la verdad y, por lo tanto, no se daba un proceso de indagación o investigación de la verdad, sino una batalla para saber quién era el más fuerte. Si no se aceptaba la prueba se perdía el proceso y, en caso de aceptarla, se concluía con una victoria o con un fracaso. En tales procedimientos la separación entre verdad y error no existe y "el juez no atestigua acerca de la verdad, sino tan sólo de la regularidad del procedimiento" (Foucault, 2008: 74). La prueba, no obstante, no es un operador de la verdad sino de derecho; establece quién es el más fuerte. Es un shifter, que opera posibilitando el pasaje de la fuerza al derecho. Este tipo de verdad 
interna o procedimental continúa gobernado en la actualidad los procesos jurídicos, rigiendo el carácter de la prueba: el material probatorio no establece una verdad fáctica, sino que se constituye como tal si cumple con los principios y procedimientos inmanentes y ya establecidos por el derecho mismo.

Como se ha mencionado anteriormente, en la segunda mitad de la Edad Media, y bajo otra forma, reapareció la indagación. En tal período se produjo una mutación en las prácticas sociales a partir de la invención de nuevas formas judiciales. Las monarquías occidentales, según Foucault, pudieron establecerse, gracias a la apropiación de la justicia, que les permitía aplicar mecanismos de confiscación para el control de la circulación de bienes. Debido a que el procurador ante una infracción al rey pasaba a ocupar su lugar en tanto víctima merecida de reparación y, ya que el rey no podía arriesgar su vida o sus bienes en cada litigio, surgió la necesidad de poner fin al modelo bélico a partir de un mecanismo nuevo, diferente de la prueba. El soberano no podía seguir presentándose en pie de igualdad. Como solución a tal problema se disponía de dos modelos ya existentes. El primero de ellos, intra-jurídico: la figura del delito flagrante. Éste se aplicaba cuando el individuo era sorprendido cometiendo el delito y toda la colectividad intervenía acusando: "Nosotros lo vimos haciendo tal cosa y en consecuencia hay que castigarlo y exigirle una reparación" (Foucault, 2008: 74). El segundo, extra-judicial (del imperio carolingio) fue la indagación. Llevada a cabo por los representantes del soberano, consistía en llamar a las personas que conocían, sabían o habían visto y reunirlas para que deliberasen. Es un "tipo de establecimiento de la verdad totalmente relacionado con la gestión administrativa de la primera gran forma de Estado conocida occidente" (Foucault, 2008:83). Por otro lado, en la conquista se utilizó la indagación administrativa para saber el estado de las propiedades. Sus características fueron: 1) el poder político es el personaje central; 2) el poder se ejerce, en principio, haciendo preguntas, cuestionando. No sabe la verdad y se procura saberla; 3 ) para determinar la verdad, el poder se dirige a los notables, personas que considera capaces de saber debido a sus situación, edad, riqueza, notoriedad, etc.; 4) el poder consulta a los notables sin forzarlos a decir la verdad mediante el empleo de la violencia, la presión o la tortura. Se les pide que se reúnan libremente y que den una opinión colectiva; que colectivamente digan aquello que consideren es la verdad.

Tales prácticas habrían caído en el olvido en el alto feudalismo (SX y XI) de no haber sido utilizadas y sostenidas en el tiempo por la iglesia con fines espirituales para la gestión de sus bienes: el obispo visitaba sus comarcas preguntando a los más virtuosos las faltas ocurridas durante su ausencia. La indagación es un modelo espiritual y administrativo, religioso y político, un modelo de origen religioso y administrativo ligado al estado que será recobrado por el procedimiento judicial. Es un modo de gestionar, vigilar y controlar las almas ya que consiste en una mirada sobre bienes y riquezas así como sobre los corazones, actos e intenciones. Fue reutilizada y ampliada en cuanto a su función inicial por el procurador del rey para desempeñar la función del delito flagrante:

Si se consigue reunir efectivamente a las personas que pueden garantizar bajo
juramento que vieron, si es posible establecer por medio de ellas que algo sucedió
realmente, podrá obtenerse indirectamente, a través de la indagación y por medio
de las personas que saben el equivalente del delito flagrante (Foucault, 2008: 85).

A partir del entrecruzamiento entre la indagación y el delito flagrante se comienzan a tratar y juzgar actos que ya no necesitan estar en el campo de la actualidad, alcanzando así una:

(...) nueva manera de prorrogar la actualidad, de transferirla de una época a otra y ofrecerla a la mirada, al saber, como si aún estuviese presente. Esta inserción 
del procedimiento de indagación reactualizado, haciendo presente, sensible, inmediato, verdadero, lo ocurrido, como si lo estuviésemos presenciando, constituye un descubrimiento capital (Foucault, 2008: 86).

Se trata de la emergencia de una nueva tecnología -de un modo de establecimiento de la verdad en una configuración de saber-poder determinada- basado la actualización de hechos de "un pasado" a "un presente" a través de la indagación de aquellos que experimentaron (vieron, escucharon, etc.) constituye un descubrimiento capital, ya que es aquello que explica el surgimiento de la figura del testimonio y de la disciplina histórica misma. No fue debido a un progreso automático de la razón que se llegó al proceso de indagación, sino a una transformación política -desplazamiento y reutilización de un procedimiento en un dominio determinado-, a la confiscación de "un proceso de gobierno, una técnica de administración, una modalidad de gestión (...) una determinada manera de ejercer el poder" (Foucault, 2008: 86).

La indagación reorganizó todas las prácticas judiciales y se extendió a otros dominios de prácticas y de saber. Sus procedimientos se expandieron por la sociedad, en el campo del conocimiento dio lugar a las ciencias de la observación. Pero, sobre todo, es una forma política devenida -a través del derecho- procedimiento y modo de producción y trasmisión de verdad. En tal sentido el autor sostiene que:

(...) la indagación no es en absoluto un contenido, sino una forma de saber, situada en la conjunción de un tipo de poder y ciertos contenidos de conocimiento (...) es precisamente una forma política, de gestión, de ejercicio del poder que, por medio de la institución judicial, pasó a ser, en la cultura occidental, una manera de autentificar la verdad, de adquirir cosas que habrán de ser consideradas como verdaderas y de transmitirlas (Foucault, 2008: 92).

Con la modernidad, en los siglos XVII y XVIII, surge el panoptismo; forma de saberpoder que ya no se apoya sobre la indagación (que reactualiza un acontecimiento a través de los testimonios de personas capaces de saber, por su rol destacado en la sociedad o por haber presenciado el acontecimiento) sino sobre el examen y la vigilancia. Según Foucault (1991) el modelo jurídico de representación, análisis y ejercicio del poder, entendido como represión y prohibición -basado en el "tu no debes" kantiano- es desplazado en esta nueva configuración por un ejercicio y comprensión del poder en los términos de la norma. Tal poder es positivo, materialista, individualizante y anatomizante, ya que su blanco es el cuerpo de los sujetos. La vigilancia ejerce un poder, $y$, al ejercerlo tiene la posibilidad de constituir un saber sobre aquellos a quienes vigila. Forma y transforma a los individuos -en sus gestos, creencias y comportamientos- en función de ciertas reglas. Surge así un saber de vigilancia, de examen organizado alrededor de la norma que establece qué o quién es normal y qué no lo es. Esta nueva forma de saber-poder se apoya y da lugar ya no a grandes ciencias de observación, como lo hacía la indagación, sino a un nuevo dominio de saber: las ciencias humanas -medicina, psicología, psiquiatría-. A partir de tal momento, la vigilancia, el control y la corrección pasan a ser las características de las relaciones de poder en la sociedad moderna. La teoría legalista de los años precedentes (ofuscada por la apropiación del poder central de los mecanismos de control popular) se ve enfrentada al panoptismo: una vigilancia que individualiza al autor del acto y deja de lado, o en segundo plano, la naturaleza jurídica o la calificación penal del acto en sí fijando a los individuos a un aparato de normalización. Aparecen entonces, en el siglo XIX, una serie de instituciones sobre las cuales es difícil establecer si son estatales o no que pasan a constituir un subpoder, es decir, un conjunto de pequeños poderes e instituciones situados en niveles más bajos que el Estado -la cárcel, la escuela, la fábrica, etc.-. Estos subpoderes, según el autor, funcionaron como condiciones de posibilidad de la plusganancia, permitiendo, mediante determinadas técnicas y a 
través de diversos dispositivos e instituciones, la explotación de la máxima cantidad de tiempo mediante la formación y valorización del cuerpo del individuo según un determinado sistema que implicó su transformación en fuerza de trabajo. El examen es un saber correctivo, una serie de saberes del individuo y de la normalización que proliferó en tales instituciones, generando las condiciones para la emergencia del hombre como objeto de conocimiento. A partir de entonces, se trata de indagar en los procesos que constituyen tanto al objeto como al sujeto de conocimiento en sus especificidades si se pretende responder a la pregunta por la verdad.

La otra gran tecnología de poder propia de la modernidad-que comienza en el siglo XVIII- ha sido, según Foucault, la biopolítica. Esta última consiste en el aislamiento y regulación de una vida biológica independientemente de sus cualidades políticas, culturales, civiles, etc. Surge así un objeto muy peculiar: la población; y una serie de técnicas encargadas de visibilizarla: la estadística, organismos administrativos, económicos, políticos, etc., que se encargan de una serie de nuevos problemas: la higiene pública, la curva etaria poblacional, la natalidad, la mortalidad, etc. (Foucault, 1991). El poder comienza a ocuparse del gobierno de la vida. El sexo se constituirá en bisagra o articulador entre el anatomo-poder disciplinar, que hace blanco en los individuos, y la biopolítica, que regula a las poblaciones. Esto se debe a su posición privilegiada, ya que supone regulación de la conducta y reproducción de la especie simultáneamente, entre ambas tecnologías de poder. Hacia el final de su obra Foucault retomará de Burroughs la noción de sociedad de control para caracterizar a las sociedades contemporáneas. ${ }^{1}$ En éstas el poder opera a distancia y a cielo abierto, a través de múltiples dispositivos.

Giorgio Agamben en la serie Homo Sacer retoma las elaboraciones de Foucault en torno a la biopolítica a partir de un trabajo genealógico “(...) que parte de la idea de poner en discusión el concepto de vida y su relación con el derecho". ${ }^{2}$ Sin embargo, situando su punto de emergencia ya no en el siglo XVIII, como lo hacía Foucault en Las redes del poder sino en la Grecia de Aristóteles, a partir del momento en que una vida desnuda (Bíos) es separada de la vida cualificada (Zoé); ${ }^{3}$ y luego con el derecho arcaico, con la constitución de la figura del homo sacer, dispositivo que incluye en la polis una vida desnuda mediante su exclusión. Por lo tanto, para este autor (Agamben, 2013), el estado de excepción, colapso e indistinción entre norma y excepción, sería aquello que define a la sociedad occidental. ${ }^{4}$

La distinción, esbozada por Aristóteles y desarrollada posteriormente por Arendt, de una vida biológica opuesta a las formas políticas o culturales engendra una vida a la que, a través del dispositivo del estado de excepción del derecho -con la distinciónindistinción norma/excepción-, cualquiera podrá dar muerte sin cometer homicidio. Esta interpretación de la biopolítica plantea un vínculo secreto entre los estados totalitarios, cuya operatoria consistió en llevar a su extremo el aislamiento de un cuerpo biológico dentro de su población, y la democracia occidental, donde proliferan espacios de excepción: zonas grises entre la vida y la muerte donde los sujetos son privados de derechos, excluidos de la ley mediante su inclusión en estos espacios como los "presos" de Guantánamo, los inmigrantes ilegales, los pacientes comatosos, etc. En este sentido, el límite propuesto por la ética occidental, el rol del estado en tanto garante de los derechos humanos -de la vida biológica de una población-fortalece, en lugar de interrumpir, a la maquinaria biopolítica. La operación de esta última consiste en la creación constante de la cesura entre bios y zoé -o vida cualificada (forma de vivir) y vida natural o biológica-incorporando la segunda a los cálculos del poder estatal para luego excluirla por medio de su inclusión en una nuda vida (vida que jamás alcanza el estatuto de bíos). El homo sacer sería, por lo tanto, aquella vida fuera de la ley (tanto de las leyes del hombre como de los dioses) insacrificable, a la que no se le puede cometer homicidio; o más bien a la que todos pueden dar muerte sin que ello implique su calificación como homicidio.
1. Véase Deleuze (2006) y Lazzaratto (2006).

2. Véase Agamben (2013).

3. Dicha distinción es rastreada por el autor en Homo Sacery en Lo Abierto. En el primer caso a partir de la descripción que hace del concepto de política en la Grecia aristotélica Hannah Arendt en La condición humana, y en el segundo parte de la distinción trazada por Aristóteles entre vida nutritiva y vida políticamente cualificada.

4. Es materia de discusión si es compatible con la teoría foucaultiana el recorte de períodos históricos tan amplios. Sin embargo, es posible esgrimir, siguiendo la interpretación que hace Deleuze en sus cursos sobre la obra del autor, que Foucault hacia el final de su producción se encontraba indagando períodos más remotos para reconstituir los diferentes estratos que continúan operando en la modulación de los procesos de subjetivación contemporáneos. Asimismo, el método genealógico propone un uso de la historia y del pasado que indague en sus archivos para quebrar y rearticular problemáticas actuales. Asimismo, también serían coherente con los desarrollos de Foucault las indagaciones teológicas de Agamben, en tanto el primero sugiere no la suplantación y recorte de épocas en términos de adecuación respecto a una tecnología de poder que la regiría sino a la coexistencia, superposición, reactualización y dominación de unas tecnologías de poder sobre otras. 
5. Para un detallado análisis véase Ferrajoli (2001).

6. La responsabilidad, según su origen jurídico y etimológico presupone salir garante de alguno (o de sí mismo) en relación a algo y frente a alguien. Constituye, por lo tanto, un gesto jurídico no uno ético. Ob-ligarse implicaba, cuando el vínculo jurídico se hallaba ligado al cuerpo del responsable, constituirse en cautivo para garantizar una deuda y se vincula al de culpa: imputabilidad de un daño. "Asumir una culpa y una responsabilidad (...) significa salir del ámbito de la ética para entrar en el del derecho" (Agamben, 2005: 23).

7. Como señala tal autor la etimología de la palabra potencia apunta tanto a potencia como a posibilidad. 8. La potencia debe ser entendida como del que ya tiene una habilidad opuesta a una potencia genérica, es decir, de aquel que aún no la tiene y podría llegar a adquirirla.
Retomando la problemática del testimonio, Agamben, señala que:

(...) en latín hay dos palabras para referirse al testigo. La primera, testis, de la que deriva nuestro término 'testigo', significa etimológicamente aquel que se sitúa como tercero (terstis) en un proceso o un litigio entre dos contendientes. La segunda superstes, hace referencia al que ha vivido una determinada realidad, ha pasado hasta el final por un acontecimiento y está, pues, en condiciones de ofrecer un testimonio sobre él (Agamben, 2005: 15).

En referencia al testimonio de Primo Levi sostiene que no es un tercero por ser un superviviente. Su testimonio no tiene que ver con el establecimiento de los hechos con vistas a un proceso ya que no es lo suficientemente neutral para ello, no es un testis. Incluso tampoco es el juicio lo que le importa, ya que debido al carácter autorreferencial de la ley el fin último de la norma es la producción del juicio. La esencia de toda ley es el proceso (alcanzar los mecanismo y criterios suficientes para la validez de la prueba), es decir no una verdad trascendente sino una verdad procesal, inmanente al proceso jurídico. ${ }^{5}$ Agamben concluye que si el derecho es sólo derecho (y moral) procesal y la moral se halla contaminada por él, ejecución y transgresión, inocencia y culpabilidad, obediencia y desobediencia se confunden y pierden importancia. Esta auto-referencialidad da como resultado que el derecho no tienda al establecimiento de la justicia, ni siquiera al de la verdad y, por lo tanto, que la pena no siga al juicio, sino que éste sea él mismo la pena o la pena como prolongación del juicio. En la misma línea, tras señalar que casi todas las categorías de la moral o religiosas (culpa, responsabilidad, inocencia, juicio, absolución) se hallan contaminadas por el derecho propone que:

(...) el derecho no albergue la pretensión de agotar el problema. La verdad tiene una consistencia no jurídica, en virtud de la cual la questio facti no puede ser confundida con la questio iuris. Esto es, precisamente lo que concierne al superviviente: todo aquello que lleva a una acción humana más allá del derecho, todo aquello que la sustrae radicalmente al proceso (Agamben, 2005: 16).

Como corolario propone deslindar verdad y derecho, cuestión fáctica de cuestión jurídica.

Otra de las hipótesis de Agamben es que a partir de Auschwitz lo que sucede con la máquina biopolítica de occidente es que su exterior y su interior, o la norma y la excepción, se precipitan tornando indistinguibles ciertas categorías centrales del pensamiento moderno. A raíz de esto último estaríamos asistiendo a la reconfiguración de los conceptos de sujeto, objeto, experiencia, verdad, ética, moral, voluntad, etc. y a una reorganización de sus relaciones. Ejemplo de ello es el análisis que efectúa del concepto de responsabilidad, categoría central de la ética moderna y, al igual que las anteriores, íntimamente ligada al derecho ${ }^{6}$. Estos aspectos de la imputabilidad jurídica que luego fueron transferidos hacia el exterior del derecho prueba, según el autor, la dificultad de cualquier doctrina ética que proponga fundarse en tales conceptos.

A continuación, se hará un recorrido por las problemáticas de la potencia y el testimonio para indagar finalmente en los vínculos entre el lenguaje, los enunciados, el testimonio, y el archivo. Según Agamben, el problema de la potencia ${ }^{7}$ parte de las siguientes preguntas delineadas por Aristóteles: “¿Qué significa tener una facultad? y ¿En qué modo existe algo así como una facultad?" La doctrina de la potencia sería una arqueología de la subjetividad, y lo más curioso aún, el surgimiento del problema del sujeto en un pensamiento que aún no contiene tal noción. Tener una potencia ${ }^{8}$ o 
tener una facultad significa tener una privación, es decir, la posibilidad de no poner en acto una facultad que se posee: "La potencia es definida, así, esencialmente por la posibilidad de su no-ejercicio" (Agamben, 2005: 16). La facultad no sólo se posee en el momento de ejercerla, ya que quien posee una facultad la sigue poseyendo aun cuando no la esté ejerciendo (la potencia, según Aristóteles, no existe sólo en acto, de ser así, el arquitecto sólo sería arquitecto cuando construye). Sin embargo, lo que lo diferencia de alguien que no tiene dicha potencia es que puede no construir, no ejercer dicha potencia, mientras que el primero queda excluido de dicha posibilidad. Se debe comprender entonces que "hay un forma, una presencia de lo que no está en acto, y esta presencia privativa es la potencia" (Agamben, 2007: 356). Sobre el plano de la potencia negación y afirmación no se excluyen. La auto-afección existe en tanto la "potencia de" no es un existente ni tampoco simple ausencia: im-potencia quiere decir potencia de no pasar al acto. Voz y letra, significación y presencia difieren infinitamente. La autoridad del testimonio:

no depende de una verdad factual, de la conformidad entre lo dicho y los hechos, entre la memoria y lo acaecido, sino de la relación inmemorial entre lo indecible y lo decible, entre el dentro y el fuera de la lengua (Agamben, 2005: 165).

La figura del testigo resulta paradigmática de esta relación entre el lenguaje y el lugar de lo humano ya que da cuenta de la desconexión entre hombre, lenguaje y experiencia; deshace la categoría principal del derecho: la conciencia. La experiencia es entendida ya no como un cúmulo de hechos o de positividades narrables, sino como la narración, cercana tal vez a un balbuceo, de la imposibilidad de la soberanía lingüística. El lenguaje se muestra en su ineficacia para dominar el mundo, tanto para ordenar los acontecimientos como para situarlos en relación al narrador. Se narra en nombre de otro que ya no está y lo que se narra es la experiencia de no ser sujeto. El testigo nos hace asistir a la experiencia propiamente dicha: al momento en que el lenguaje no se halla en posesión del hombre. Si el sujeto sólo puede dar cuenta de sí a través de enseñar su potencia de no ser sujeto; subjetivación y desubjetivación, o lo humano y lo inhumano, forman parte un mismo proceso donde, si bien no pueden ser pensadas por separado, tampoco se indistinguen. El testimonio se ubica precisamente en la fractura de ambos. No se puede seguir hablando de una conciencia como centro de hábitos y facultades ya que toda subjetividad está signada o recorrida por corrientes de desubjetivación.

Agamben propone como tarea, a partir del problema de la influencia del discurso jurídico y religioso sobre la ética, identificar el lugar y el sujeto del testimonio para "plantar jalones para orientar a los cartógrafos de la nueva ética". En tal sentido, si la figura del testigo integral es la del musulmán,? es decir, aquel que habría "experimentado" la desubjetivación o franqueado el límite de lo humano, surge la pregunta acerca del sujeto del testimonio: ¿quién testimonia si el superviviente testimonia por cuenta de o por delegación del musulmán? Además si según un principio jurídico los actos del delegado se atribuyen al delegante, es el musulmán el que testimonia. Es decir, el no-hombre testimonia sobre el hombre y éste último le presta su voz. Tal paradoja marca una insuficiencia tanto del humanismo como del anti-humanismo ya que el testimonio precisa que "Los hombres son hombres en cuanto testimonian del no-hombre" (Agamben, 2005: 127).

El carácter más específico de la biopolítica del siglo XX ya no sería, según la definición de Foucault, hacer morir ni hacer vivir, sino hacer sobrevivir: una supervivencia modulable y virtualmente infinita; la producción de una vida -es decir una nuda vidaprivada de todo tipo de cualidad e incapaz de testimoniar. El musulmán y el utracomatoso representan la cifra secreta del biopoder, ${ }^{10}$ el lugar en que coinciden la faz visible y la faz oculta del poder.
9. La figura del musulmán hace referencia a aquellos prisioneros de Auschwitz que parecían haber perdido toda capacidad de lenguaje y casi todo tipo de contacto con el mundo exterior que no se redujese a las actividades mínimas o "biológicas" de supervivencia (vestimenta, alimentación, etc.) 
En el musulmán, el biopoder ha pretendido producir su último arcano, una supervivencia separada de cualquier posibilidad de testimonio, una suerte de sustancia biopolítica absoluta que, en su aislamiento, permite la asignación de cualquier identidad demográfica, étnica, nacional o política (Agamben, 2005: 163).

El musulmán es el intento de aislar una nuda vida inasignable e intestimoniable, de desarticular su relación con el polo subjetivo, donde el nexo entre subjetivación y desubjetivación se deshace. Siguiendo a Benveniste el autor postula que el fundamento de la subjetividad se halla en el ejercicio de la lengua y, en consecuencia, que la conciencia no tiene otra consistencia que no sea la del lenguaje. Gracias a la presencia a sí mismo como yo, como locutor, se produce en el viviente algo semejante a un centro unitario de imputación de los actos y vivencias sustraído del océano de las sensaciones y los estados psíquicos. En tal concepción del enunciado la temporalidad humana se genera a través de la presencia a sí mismo y al mundo que el acto de enunciación hace posible. Se vive el ahora por la inserción del discurso en el mundo; el viviente ocupa el lugar del sujeto a través de la enunciación, más precisamente por medio de los deícticos, al decir: yo, ahora. Es decir, no tiene otra realidad más que la del discurso. Sin embargo:

(...) al decir yo, hace retroceder a un pasado sin fondo sus vivencias, no puede coincidir inmediatamente con ellas. La instancia de discurso en el puro presente escinde irremediablemente la presencia ante sí mismas de las sensaciones y de las vivencias en el momento mismo en que las refiere a un centro de imputación unitario (Agamben, 2005: 128).

La conciencia, prosigue el autor, está construida sobre una separación: la constitutiva desubjetivación de toda subjetivación. La no coincidencia entre el yo y sus vivencias es algo habitual en el hombre. En tal sentido, los testimonios de los sobrevivientes de Auschwitz serían aquello que da cuenta de la experiencia del sujeto en el lenguaje ya que plantean esta escisión de las vivencias que nunca pueden coincidir con el sujeto. Y en el caso específico del testimonio porque se trataría de testimoniar la experiencia de la desubjetivación, de haber "habitado" lo inhabitable. Un afuera que no es el del mundo animal, ya que los animales poseen lenguaje pero no la posibilidad de no ejercerlo. Si el afuera es el lenguaje como potencia, como facultad que puede ser ejercida, es decir la posibilidad de no pasar al acto, el musulmán estaría privado de dicha potencia. Testimoniar sería, por lo tanto, dar cuenta de la exposición a un afuera radical, a la experiencia de asistir a la imposibilidad misma de la experiencia, hacer la experiencia de la impotencia de la experiencia. En el testimonio resulta imposible asignar la posición de sujeto al hablante, ya que se trata de un sujeto hablando desde una posición de no-sujeto. Esto último se debe a que el testimonio:

(...) contiene, en su centro mismo, algo que es intestimoniable, que destruye la autoridad de los supervivientes" porque los testigos testimonian de un testimonio que falta: "los hundidos no tienen nada que decir ni instrucciones ni memorias que transmitir (...) Quien asume la carga de testimoniar por ellos sabe que tiene que dar testimonio de la imposibilidad de testimoniar. Y esto altera de manera definitiva el valor del testimonio, obliga a buscar su sentido en una zona imprevista (Agamben, 2005: 34).

11. Tales desarrollos que en Infancia e historia eran retomados de Benjamin, que consideraba que la experiencia se perdía en la modernidad y era producto histórico de una época, cambian su sentido al pasar a ser la condición de todo hablante.
Por lo tanto, el testimonio, y el hecho de que apunte a la imposibilidad de una experiencia adjudicable a una conciencia individual, o al menos de que en la experiencia está inscrita su impotencia, constituye un ejemplo paradigmático que apunta a las condiciones del sujeto. ${ }^{11}$ Para Agamben, la novedad del método foucaultiano es no haber tratado de aprehender el tener lugar del lenguaje por medio de un yo o de una conciencia trascendental, sin embargo, la constitución del sistema de enunciados en 
una positividad y en un a priori histórico ha hecho que se olvide la desaparición del sujeto, que era su presupuesto indispensable. La preocupación por descartar la pregunta ¿Quién habla? impidió formular la pregunta:

¿Qué sucede en el individuo viviente en el momento en que ocupa el 'puesto vacío' del sujeto, en el punto en que, al entrar en un proceso de enunciación, descubre que "nuestra razón no es más que la diferencia de los discursos, que nuestra historia no es más que la diferencia de los tiempos, que nuestro yo no es más que la diferencia de las máscaras?" (Agamben, 2005: 149).

Es decir, qué significa ser sujeto de una desubjetivación, cómo puede un sujeto dar cuenta de su propia disolución. Tal limitación, continúa, no se debe a Foucault sino que está implícita en el concepto mismo de una semántica de la enunciación [que retoma de Benveniste]. Su tener lugar no se funda sobre un contenido de significado sino sobre un acontecimiento de lenguaje. El sujeto de la enunciación "no puede tomarse a sí mismo como objeto, enunciarse. No puede haber, pues, una arqueología del sujeto como hay una arqueología de los saberes" (Agamben, 2005: 149). Por consiguiente plantea desplazarse al plano de la lengua, o más bien entre la lengua y el archivo, no entre un discurso y el hecho de que tenga lugar sino entre "una pura posibilidad de decir" y su existencia como tal. La enunciación está entre la langue y la parole, se debe considerar a los enunciados no desde el discurso en acto en tanto acto de palabra sino hacia la lengua: “(...) La articulación entre un dentro y un fuera no sólo en el plano del lenguaje y del discurso en acto, sino también en el de la lengua como potencia de decir" (Agamben, 2005: 151). El archivo, que designa el sistema de las relaciones entre lo no dicho y lo dicho, dejaba al margen al sujeto mientras que la cuestión decisiva del testimonio es el puesto vacío del sujeto. Situar al sujeto en la separación de una posibilidad y una imposibilidad de decir, entre lo decible y lo indecible de toda lengua. ${ }^{12}$

Lo que distingue al hombre del resto de los vivientes, según Agamben, es que mantiene su hacer o su comportarse en tensión con su no-hacer o su no-comportarse, con su impotencia. Los segundos pueden sus comportamientos específicos y a ello se debe su calidad de instintos o inscripción biológica.

Toda potencia humana es, cooriginariamente, impotencia; todo poder-ser o poder-hacer está, para el hombre constitutivamente en relación con la propia privación. Y este es el origen de la desmesura de la potencia humana, tanto más violenta y eficaz respecto de la de los otros seres vivientes. Los otros vivientes pueden sólo su potencia específica, pueden sólo este o aquel comportamiento inscripto en su vocación biológica; el hombre es el animal que puede la propia impotencia. La grandeza de su potencia se mide por el abismo de su impotencia (Agamben, 2007: 362).

Ya que tener la potencia de ejercer una facultad no es del orden de lo que puede ser poseído -como sucede en el resto de los vivientes- o, más precisamente, en tanto implica al mismo tiempo una potencia-de-no, se presenta en el hombre la imposibilidad de una conciencia auto-reflexiva como centro de imputación de hábitos y facultades. En Infancia e Historia la diferencia entre el hombre y el animal es invertida. Los animales poseen lenguaje y los hombres se mantienen en una relación de im-potencia éste, es decir, pueden no ejercer dicha facultad. Mientras que en los primeros hay coincidencia entre los comportamientos con los desinhibidores de su circunmundo ${ }^{13}$ los segundos estarían expuestos a lo abierto por su relación específica con el lenguaje. El hombre es el viviente que no tiene lenguaje precisamente porque no se halla atado a la lengua, porque puede su impotencia respecto de ella, es capaz de infancia. La infancia es la posibilidad en el hombre -en tanto viviente- de que la lengua no esté en él.
12. En este punto es nuevamente estimulante leer La subjetivación. Curso sobre Foucault de Gilles Deleuze. Esta lectura propone que el eje de la subjetivación en Foucault es lo que permite articular los ejes del saber y del poder a partir de una perspectiva que no sólo explica el tramos final de su obra en torno a la ética y la estética de la existencia sino también a su necesidad del trabajar con períodos históricos más extensos. El eje de la subjetivación no sólo los exigiría sino que estaría dando cuenta justamente del afuera del archivo al que alude Agamben.

13. Si bien el desarrollo de estos tópicos pueden hallarse en Lo Abierto siguen el camino trazado tanto por Von Uexqüll como por las lecturas que Heidegger hizo de éste último. 
14. Foucault se refiere alli a la literatura como el afuera donde desaparece el sujeto que habla: "el ser del lenguaje no aparece por sí mismo más que en la desaparición del sujeto" (Foucault, 2004: 16)
(...) en ninguna parte nos es dado alcanzar, en el viviente o en el lenguaje, un punto en que se produzca algo realmente similar a una articulación (...) Pero es justamente esta imposibilidad de mantener reunidos al viviente y el lenguaje, la phoné y el logos, lo no-humano y lo humano, la que-lejos de autorizar que la significación quede diferida infinitamente- permite que se produzca el testimonio. Si no hay articulación entre el viviente y el lenguaje, si el yo queda suspendido en esa separación, entonces puede darse testimonio. La intimidad, que traduce nuestra no-coincidencia con nosotros mismos, es el lugar del testimonio. El testimonio tiene lugar en el no-lugar de la articulación. En el no-lugar de la Voz no está la escritura sino el testigo. Y precisamente porque la relación (o más bien la no relación) entre el viviente y el hablante reviste la forma de la vergüenza, de estar recíprocamente consignados a un inasumible, el ethos de esa separación no puede ser otra cosa que un testimonio; algo, pues, que no se puede asignar a un sujeto, y que constituye, no obstante, la única morada, la única consistencia posible de un sujeto (Agamben, 2005: 136-137).

En la cita resuenan algunos de los motivos Elpensamiento del afuera de Foucault. Obra en la que son exploradas las relaciones entre el afuera, el lenguaje, la ley, la intimidad y la literatura ${ }^{14}$. Sin embargo, en la cita en el lugar donde aparecía la escritura está el testigo y en el de la intimidad la vergüenza. En Sobre la dificultad de leer Agamben vuelve a la pregunta por el estatuto del testigo -emparentado esta vez con aquel que escribe por o en el lugar del analfabeto a partir de la pregunta por lo ilegible. Lo ilegible en la lectura y lo ilegible en la escritura: escrituras que no han de ser leídas y lecturas que no se corresponden con lo escrito, la ilegibilidad del mundo y la impotencia de cualquier libro que pretenda develarlo. Luego de plantear que la literatura italiana nace íntimamente ligada a la oralidad sugiere que tal vez aquello que precede a la escritura y a la escritura sea la oralidad: "cuando Dante decide escribir en lengua vulgar", se pregunta si la intraductibilidad del dialecto de la poesía italiana opera como un "reclamo de aquella ilegible oralidad" y memoria del analfabetismo. Lo que nunca ha sido escrito y se escapa entre las páginas del libro, la poesía que restituye lo ilegible en la lengua, sería entonces "aquel parlar materno analfabeto que existía en la oralidad". 


\section{Q Bibliografía}

"Agamben, G. (2002) Homo Sacer I. El poder soberano y la nuda vida. Madrid: Editora Nacional.

"Agamben, G. (2005) Lo que queda de Auschwitz. El archivo y el testigo. Homo sacer III. Valencia: Pre-textos.

"Agamben, G. (2016) El fuego y el relato. Madrid: Sexto Piso.

》Agamben, G. (2007) La potencia del pensamiento. Buenos Aires: Adriana Hidalgo.

» Agamben, G. (2013) "En Europa asistimos a un vaciamiento de la democracia", en Adn Cultura, diario La Nación, 22-3-2013.

"Agamben, G. (2014) "Sobre la dificultad de leer" en El fuego y el relato. Madrid, Sexto piso.

»Deleuze, G. (2006) Post-scriptum sobre las sociedades de control, Polis, Revista de la Universidad Bolivariana, vol. 5, núm. 13, 2006. Disponible en: <http://www. redalyc.org/articulo.oa?id=30551320>.

"Ferrajoli, L. (2001) Derecho y razón. Teoría del garantismo penal. Madrid: Trotta.

" Foucault, M. (1991) Las redes del poder. Buenos Aires: Almagesto/Colección mínima.

》 Foucault, M. (2004) El pensamiento del afuera. Valencia: Pretextos.

"Foucault, M. (2008) La verdad y las formas jurídicas. Barcelona: Gedisa.

» Lazazrato, M. (2006) Políticas del acontecimiento. Buenos Aires: Tinta Limón. 
